\title{
Un caso de elaboración narrativa de experiencias concretas en "La Ciudad y los Perros"
}

\author{
por \\ Pedro Lastra
}

Un apreciable sector de la crítica internacional que se ha referido a la novela $L a$ ciudad y los perros, del escritor peruano Mario Vargas Llosa(1), destaca cierto prurito de exactitud en el novelista, una tenaz preocupación por transmitir observaciones más 0 menos precisas de la realidad que constituye el sustrato de su obra. Es efectivo que el autor estudió en el Colegio Militar Leoncio Prado, plantel que sirve de escenario a gran parte de la novela; además, las cuatro ediciones de Seix Barral se abren con un "Plano de la ciudad de Lima metropolitana", que permite seguir con fidelidad el desplazamiento de los personajes (2). Ambos datos -un momento de la biografía de Vargas Llosa y la presencia de ese plano en el volumen-teparecen haber condicionado negativamente a un buen número de críticos de $L a$ ciudad y los perros, con perjuicio evidente para el mejor rendimiento del análisis de una obra de estructura compleja y de riquísimo contenido simbólico (3). De este modo, no resulta extraño que - desde distintos ángulos- se haya tratado con exceso de fijar la implicación autobiográfica, reconociendo incluso

(1) Barcelona, Seix Barral, 1963. 347 p. Premio Bibloteca Breve 1962; Premio Crítica 1963. Unico manuscrito en lengua española presentado al Premio Formentor 1963, donde obtuvo 3 votos sobre 7. Cuarta edición: septiembre de 1964. Mario Vargas Llosa (1936) ha publicado también un libro de cuentos, Los Jefes, Barcelona, Rocas, 1958.

(2) El "Plano.." no aparece en la edición de Lima, Populibros Peruanos (1964). 339 p.

(3) La novela de Vargas Llosa ha merecido una atención crítica extraordinariamente sostenida; entre el vasto material existente que nos ha sido posible consultar, sobresalen, sin contrapeso, tres estudios notables: Alberto Escobar: "Impostores de sf mismos". En Revista Peruana de Cultura, Lima, No 2, julio 1964. Pp. 119. 125; Jorge Raúi Lafforgue: "Mario Vargas Llosa, moralista". "En Capricornio, Buenos Aires, (Segunda época), año I, Núm. 1, mayo-junio 1965. Pp. 48-72; Raúl H. Silva Cáccres: "Mario Vargas Llosa: Ln cludad y los perros. Biblioteca Breve Barcelona. Editorial Seix Barral, 1963); 343 págs." Reseña bibliográfica en Cuadernos Hispanoamericanos, Madrid, t. LVIII, Nọ 173, mayo 1964. Pp. 416-422. 
al autor en el personaje Alberto Fernández, denominado el Poeta, o que se acuda a la existencia del Plano como si se tratara de una irrecusable afirmación de verismo.

Acerca de una de esas preocupaciones interpretativas ilustra este instante de la mesa redonda sobre La ciudad $y$ los perros, realizada en la Casa de las Américas, de La Habana, el 29 de enero de 1965, entre Luis Agüero, Juan Larco, Ambrosio Fornet y el propio novelista:

Agüero: Por supuesto, usted estudió en el Leoncio Prado... Vargas Llosa: Sí, estuve dos años.

Agüero: ¿Hlay elementos autobiográficos en la novela?

Vargas Llosa: Bueno, en la medida en que todo autor es autobiográfico. Los escritores sólo pueden escribir sobre la realidad en función de su experiencia personal, y, claro, en la novela yo he volcado una experencia, he tratado de ser ficl, en todo lo posible, al ambiente del Leoncio Prado que yo conocí. Desde luego, la novela es una ficción. Mi intención no era contar un hecho de mi vida, sino recrear un ambiente que a mí me impresionó y que en cierta forma me obsedía, me perseguía. Pero yo creo que este es un fenómeno muy frecuente en la literatura. Un autor que escribe sobre Marta, vuelca una experiencia personal.

Agüero: Yo le hacía esa pregunta porque imaginaba que el personaje de Alberto...

Vargas Llosa: Bueno, eso me han dicho... pero en realidad yo no me reconozco absolutamente en Alberto (4).

Con demasiadar frecuenciaellá inversión o confusión de términos como "verosímil" y "verídico" suele impedir el acceso al sentido último de una novela. El ensayista Alberto Escobar ha puntualizado así el problema, en su penetrante comentario sobre La ciudad y los perros:

...la novela crea realidad, la transforma y perfecciona: es un camino imaginario hacia lo real, a través de la experiencia imaginaria de una criatura imaginaria, pero que se confunde con la realidad. $[\ldots .$.$] la novela apunta a lo real por$ lo imaginario, mientras la lírica a lo imaginario por lo real. La lírica es éxtasis, maravilla; la novela, conocimiento constructivo, percepción totalizadora (5).

Es por esto que Escobar no considera indispensable es-

(4) Luis Agüero, Juan Larco, Ambrosio Fornet, Mario Vargas Llosa. "Sobre La cludad y los perros, de Mario Vargas Llosa". En Casa de las Américas. La Habana, año V, Nọ 30, mayo-junio 1965. Pp. 63-80. La cita corresponde a las pp. 75-76.

(5) Alberto Escobar. Loc. cit., p. 120. 
clarecer si la materia que usa el novelista es verídica o inventada:

...digamos -agrega-, a fin de llegar a un acuerdo, que lo sensato será presumir que es posible que ella sea de una u otra indole, o que el autor haya tomado pie en situaciones y caracteres conocidos, para luego conferirles la virtualidad de un desarrollo imaginario. Es decir, que el autor nos ha enfrentado a una serie de personajes y normas que se han ensamblado en la obra al servicio de una finalidad interna: su destino imaginario; y más adelante, concluída la lectura del libro, después de haber asistido al desarrollo de ese destino, inferimos una verdad externa, que no atañe al Colegio Leoncio Prado en particular, o que le atañe en la proporción que a cualquier sociedad cerrada, presuntamente distinta de la comunidad que la genera y la surte (6).

Las observaciones de Escobar apuntan a una exigencia básica del género, que atiende al grado de elaboración de los materiales - los que pueden estar constituídos por experiencias concretas del autor- aprovechados como fundamento del desarrollo imaginario. Es en este sentido que nos ha parecido de interés confrontar dos textos de Vargas Llosa, suficientemente iluminadores de este aspecto de la creación novelística y, en particular, de la obra del escritor peruano.

El primer texto se titula "Nota sobre César Moro", y apareció en el número inicial de la revista Literatura (7), de Lima, en el mes de febrero de 1958. Se trata de un artículo en el que Vargas Llosa testimonia conmovedoramente su admiración al poetaedesaparecido en 1956, 'y cuya producción surge con caracteres excepcionales dentro de la lírica peruana, por su auténtica condición visionaria, plasmada en un lenguaje poético de extraordinario y misterioso poder.

En la breve nota, Vargas Llosa muestra - con bastante lucidez- los valores de la poesía de César Moro e indica que la orientación sui géneris de su obra lo define como un creador sustancialmente extraño en el ámbito nacional. Pero lo que sirve a nuestro propósito no es, por ahora, su apreciación crítica acerca del poeta, sino la entrañada, casi diríamos patética, visión del hombre con que empieza su artículo:

Recuerdo imprecisamente a César Moro: lo veo, entre nieblas, dictando sus clases en el colegio Leoncio Prado, im-

(6) Alberto Escobar. Loc. cit., pp. 120-121.

(7) De esta revista, creada y dirigida por Mario Vargas Llosa, Abelardo Oquendo J Luis Lonyza, sólo aparecieron tres numeros, entre febrero de 1958 y agosto de 1959. 
perturbable ante la salvaje hostilidad de los alumnos, que desahogábamos en ese profesor frio y cortés, la amargura del internado y la humillación sistemática que nos imponian los instructores militares. Alguien había corrido el rumor de que era homosexual y poeta: eso levantó a su alredecoor una curiosidad maligna y un odio agresivo que lo asediaba sin descanso desde que atravesaba la puerta del colegio. Nadie se interesaba por el curso de francés que dictaba, nadie escuchaba sus clases. Extrañamente, sin embargo, este profesor no descuidaba un instante su trabajo. Acosado por una lluvia de invectivas, carcajadas insolentes, bromas monstruosas, desarrollaba sus explicaciones y trazaba cuadros sinópticos en la pizarra, sin detenerse un momento, como si, junto al desaforado auditorio que formaban los cadetes, hubiera otro, invisible $\mathrm{y}$ atento. Jamás adulaba a sus alumnos. Nunca utilizaba a los ternibles suboficiales para imponer la disciplina. Ni una vez pidió que cesara la campaña de provocación y escarnio desatada contra el. Su actitud nos desconcertaba, sobre todo porque parccia consciente, lúcida. En cualquier momento hubiera podido corregir de raiz ese estado de cosas que, a todas luces, lo estaba destruyendo: le bastaba servirse de uno de los innumerables recursos de coacción y terror que aplicaban, en desenfrenada competencia, sus "colegas" civiles y militares; sin embargo, no lo hizo. Aunque nada sabíamos de él, muchas veces, mis compañeros y yo, debimos preguntarnos qué hacía Moro en ese recinto thúmedo e Snhóspito, desempenando un oficio oscuro y doloroso en el que parecia absolutamente fuera de lugar. (p. 5$)$.

Este fragmento de Vargas Llosa reproduce una situación real, ubicada en una época que, más adelante, se precisa: "Ocho años después me pregunto cómo situar a Moro en la poesía peruana...". Luego podremos observar cómo se transforma en la novela el conflicto del personaje concreto que es César Moro, al aparecer como conflicto de un personaje imaginario: ẹl profesor Fontana. En el artículo, Vargas Llosa nos informa acerca de un momento de su experiencia personal; en la novela, el narrador nos proveerá de "un modo de conocer", a través de la puesta en sitzlación narrativa del suceso que -nosotros lo sabemos ahora- aconteció alguna vez. Como ocurre en toda buena novela, volveremos a lo real por el camino de lo imaginario. $Y$, en este caso, enriquecidos, porque esta situación narrativa exhibe, una vez más, la fuerza comunicativa de los motivos que han sido scñala- 
dos como fundamentales de La ciudad y los perros: la violencia (8), la radical soledad del ser humano, el ejercicio de la crueldad, la superstición del machismo, la impotencia frente a la injusticia, el problema de la supervivencia del más fuerte.

El texto que nos permite el cotejo revelador de la capacidad de elaboración novelística de Vargas Llosa, se encuentra en el capítulo VII de la Primera parte de La ciudad y los perros, y corresponde a una de las secuencias de un monólogo interior del personaje denominado el Boa:

... en las clases de francés uno se divierte mucho, vaya tipo raro, Fontana. El serrano decía: Fontana es todo a medias; medio bajito, medio rubio, medio hombre. [...] Dice que no es francés sino peruano y que se hace pasar por francés, eso se llama ser hijo de perra [...] ¿de dónde sale tanta cosa que cuentan de Fontana? Todos los días sacan algo nucvo. De repente ni siquiera es marica, pero de dónde esa vocesita, esos gestos que provoca pellizcarle los cachetes. Si es verdad que se hace pasar por francés, me alegro de haberlo batido. Me alegro que lo batan. Lo seguiré batiendo hasta el último día de clase. Profesor Fontana, ¿cómo se dice en francés cucurucho de caca? A veces da compasión, no es mala gente, sólo un poco raro. Una vez se puso a llorar, crec que fue por las "Guilletes", zumm, zumm, zumm. Traigan todos una "Guillete" y párenlas en una rendija de la carpeta, para hacerlas vibrar les meten el dedito, dijo el Jaguar. Fontana movía la bocányllsólo se oíazumm, zumm, zumm. No se rían para no perder el compás, el marica seguía moviendo la boquita, zumm, zumm, zumm, cada vez más fuerte y parejo, a ver quién se cansa primero. Nos quedamos así tres cuartos de hora, quizá más. ¿Quién va a ganar, quién se rinde primero? Fontana como si nada, un mudo que mueve la boca y la sinfonía cada vez más bonita, más igualita. Y entonces cerró los ojos y cuando los abrió lloraba. Es un marica. [...] Se fue y todos dijeron "ha ido a llamar al teniente, ya nos fregamos", pero eso es lo mejor, sólo se mandó mudar. Todos los días lo baten y nunca llama a los oficiales. [‥] Los maricas son muy raros. Es un buen tipo, nunca jala en los exámenes. El tiene la culpa que lo batan. ¿Qué hace en un colegio de machos con esa voz y esos andares? El serrano

(8) Para una discusión de este motivo, confróntese la mesa redonda publicada en la revista Casa de las Américas, ya citada, donde el autor expone su punto do vista discrepante sobre el planteamiento del tema (pp. 76-77). 
lo friega todo el tiempo, lo odia de veras. Basta que lo vea entrar para que empiece, ¿cómo se dice maricón en francés?. profesor ¿a usted le gusta el catchascán?, usted debe ser muy artista, ¿por qué no se canta algo en francés con esa dulce voz que tiene?, profesor Fontana, sus ojos se parecen a los de Rita Hayworth. Y el marica no se queda callado, siempre responde, sólo que en francés. Oiga, profesor, no sea usted tan vivo, no mente la madre, lo desafio a boxear con guantes, Jaguar no seas mal educado. Lo que pasa es que se lo han comido. lo tenemos dominado. Una vez lo escupimos mientras escribía en la pizarra, quedó todito vomitado, qué asquerosidad decía Cava, debía bañarse antes de entrar a clases... (Pp. 148-149) (9).

Mario Vargas Llosa ha manifestado que "todas las técnicas deben proponerse anular la distancia entre el lector y lo narrado, no permitir que el lector, en el momento de la lectura, pueda ser juez o testigo, lograr que la narración lo absorba de tal manera que la vida del lector sea la vida de la narración y que, entonces, el lector viva la narración como una experiencia más" (10).

El modo cómo el autor ha logrado elaborar sus materiales, de acuerdo con una clara concepción teórica acerca del sentido de las situaciones narrativas desarrolladas en la obra, es lo que hemos pretendido insinuar en esta nota.

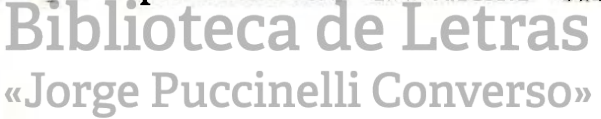

(9) Citamos por la primera edición de Seix Barral.

(10) Casa de las Américas, Nọ 30, p. 78. 